\title{
THERMO-MECHANICAL MODEL FOR CONCRETE PAVEMENT
}

\author{
Jakub VeselÝ*, VÍt ŠmilaueR \\ Czech Technical University in Prague, Faculty of Civil Engineering, Department of Mechanics, Thákurova 7, \\ 16629 Prague 6, Czech Republic \\ * corresponding author: jakub.vesely.2@fsv.cvut.cz
}

\begin{abstract}
This paper describes a numerical thermo-mechanical model for concrete pavement, implemented in OOFEM software. The thermal part is a heat transfer problem with appropriate initial and boundary conditions (sun irradiation, radiation and convection), calibrated from experimental data. Heat release from cement hydration is also included, calibrated for commonly used cements to demonstrate the difference that can be achieved with the binder selection. The mechanical part of the problem is composed of a 3D elastic concrete slab, subsoil Winkler-Pasternak elements and $1 \mathrm{D}$ interface elements, allowing separation in tension. The Winkler-Pasternak constants $\mathrm{C}_{1}$ and $\mathrm{C}_{2}$ were firstly determined from TP170 document and refined later from static load tests on the highway. The model validates well temperature field, static load test and provide several useful insight such as feasible time for summer casting, stress/strain fields and slab separation from the base.
\end{abstract}

KEYWORDS: Concrete pavement, heat transfer, thermo-mechanical analysis.

\section{INTRODUCTION}

Durability of concrete pavements presents important research topic in the world and in the Czech Republic. Recent developments in concrete pavement construction made construction process faster, but in several cases at the expense of durability. Currently adopted design approaches still heavily relies on Westergaard's theory, resulting in dominant wheel load over temperature effects [1]. However, only linear temperature profile is presumed, but in reality the thermal effects are too general, unable to be captured with classical beam/slab theory. Instead, numerical approaches are used [2].

There are several indications of decreased durability of concrete pavements. One of them lies in choosing suitable binder, where hydration kinetics and microdefects take place [3]. To demonstrate this decisive factor for durability, an experimental pilot section on a newly built part of the D1 highway was carried out, using slag-blended binder with slow hydration kinetics[4]. The monitoring of pavement is ongoing since the realization phase on one selected representative slab. There are several measured quantities, such as air temperature, sun irradiation, temperature of concrete and strains in several points in the slab. Several months after the realization, the static load test took the place.

The 3D thermo-mechanical model stems from this slab monitoring campaign and was calibrated. The model is implemented in OOFEM software $[5,6]$. The thermal task is solved first and the resulting temperature field enters into the computation of mechanical task. The boundary conditions for the thermal task are derived from measured data (air temperature, sun irradiation and radiation) and are approximated into simple functions. Elastic material properties are used to describe the mechanical task, with commonly used elastic parameters for concrete. The soil is described with Winkler-Pasternak elements, the two parameters $C_{1}$ and $C_{2}$ are determined from comparison with $3 \mathrm{D}$ continuum model and with elastic properties from TP170 [1] and from static load test results.

\section{Concrete Slab AND ITS MONITORING}

A new section of D1 highway, the key infrastructure construction in the Czech Republic, is situated in central Moravia between cities Lipník nad Bečvou and Přerov. A slow-hardening slag-blended cement was used on approximately $7 \mathrm{~km}$ length and a single slab instrumented with strain and temperature gauges. The dimensions of the slab are $5000 \mathrm{~mm}$ in length, $3750 \mathrm{~mm}$ in width and $290 \mathrm{~mm}$ in thickness, these dimensions are commonly used. Concrete pavement is constructed using two layer concrete casting, the bottom layer is $240 \mathrm{~mm}$ thick the top one attains $50 \mathrm{~mm}$. Concrete for both layers differs, the upper layer contain more binder $\left(+50 \mathrm{~kg} \mathrm{~m}^{-3}\right)$ and smaller aggregates. Concrete slab rests on compacted base course, such as MZK (compacted gravel with defined moisture) or $\breve{S} \mathrm{D}_{A}$ (vibrated gravel).

There are 18 measuring points in the slab, instrumented with strain and temperature gauges (Fig. 2). They are placed in 6 different positions (4 close to the middle of every edge and 2 in the middle of the slab) and at 3 height levels $(50 \mathrm{~mm}, 140 \mathrm{~mm}$ and 240 $\mathrm{mm}$ from the top surface of the slab). They are situated in a safe distance from the joints, dowel bars and anchors (1). 


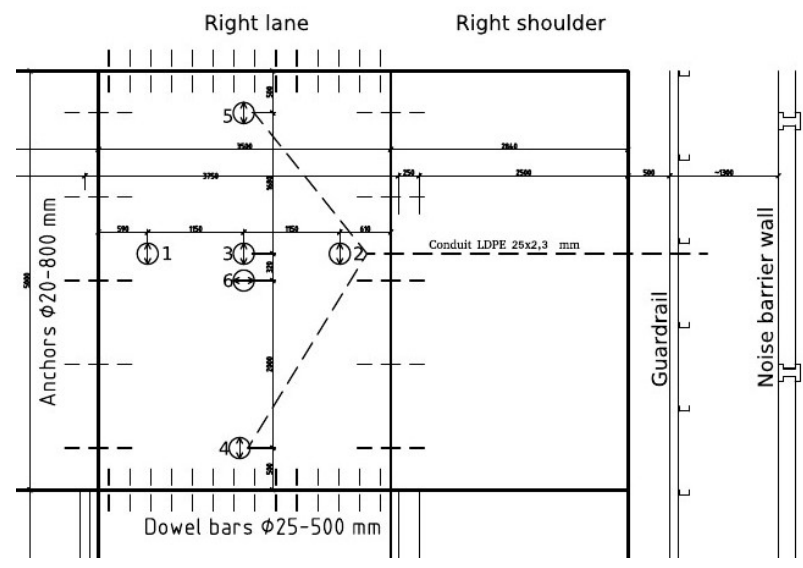

Figure 1. Plan view of the instrumented slab.

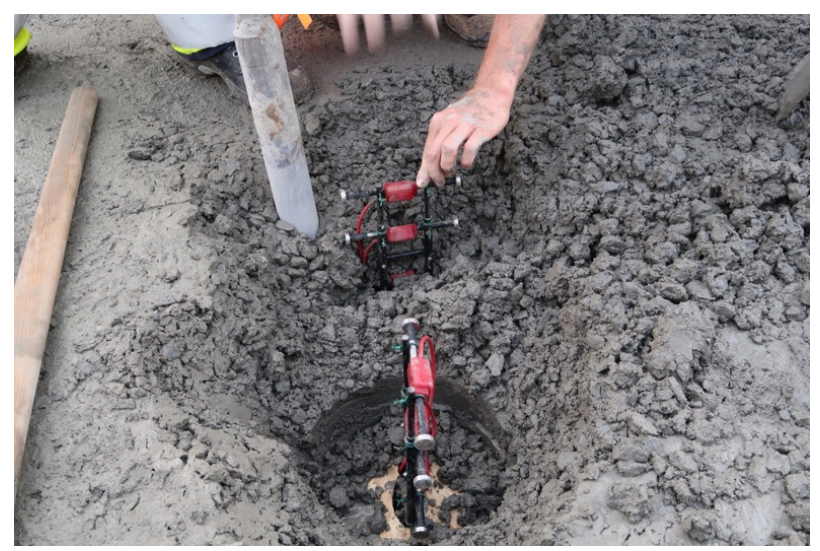

Figure 2. Measuring points in the concrete slab.

\section{THERMAL MODEL}

The thermal model is implemented in OOFEM software and solves heat transport:

$$
-\nabla^{T} q(x)+Q(x, t)=\rho(x) c_{v}(x) \frac{\partial T(x, t)}{\partial t}
$$

where $Q$ is the heat power from hydration and $T$ is the thermal field. Material properties, such as thermal capacity and conductivity are defined. The quadratic $3 \mathrm{D}$ elements are used in this model to describe well rather parabolic profile across slab's thickness. Geometry and mesh were created in Salome preprocessor, see Figure 3.

\subsection{INFLUENCE OF BINDER SELECTION FOR HEAT GENERATION}

One of the possible methods for decreasing the heat liberation is replacing the commonly used ordinary Portland cement (CEM I 42,5R) with different binders. There are several alternatives to be chosen, for example using lower cement class CEM I 32,5R or blended slag system. The differences in maximal temperatures can be seen in Figure 4 , showing $3^{\circ} \mathrm{C}$ difference during hot summer days.

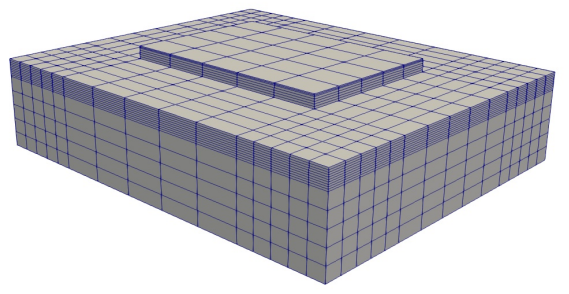

Figure 3. Mesh for the thermal model.

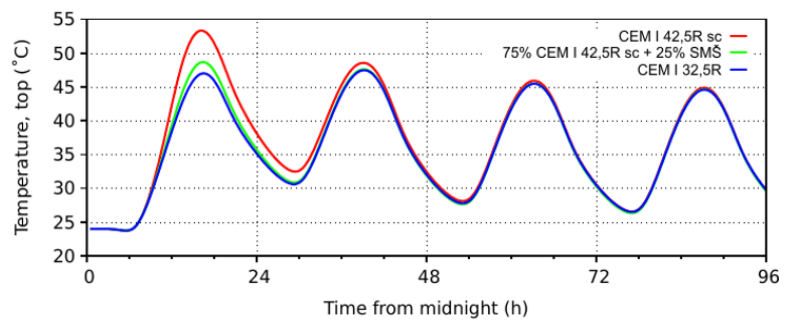

Figure 4. Temperature evolution on the top of the slab, differences in used binders.

\subsection{Optimal CASTing time}

Another possible reduction of maximum temperature happens due to appropriate time of casing. Usually, casting happens between 6-12 AM (in summer), as shown in Figure 5, but this is not the optimum since hydration power adds with sun irradiation. Casting between 1-10 PM shows much better performance, when the peak of hydration power separates from sun irradiation.

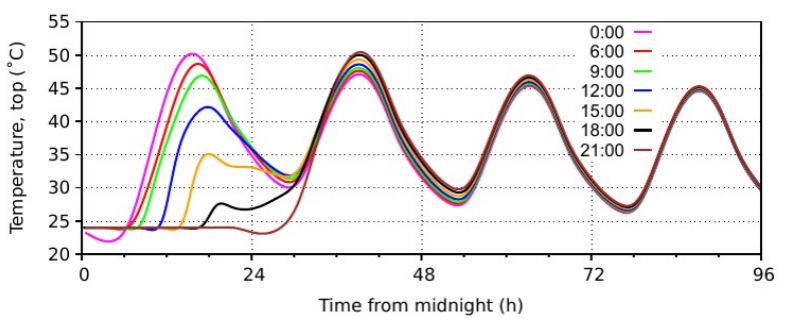

Figure 5. Temperature on the top of the slab generated from hydration with different casting times.

\section{MEChANiCAL MODEL}

The mechanical task operates on 3D elastic concrete slab with quadratic brick elements. The foundation system is simplified using Winkler-Pasternak elements, with $C_{1}$ and $C_{2}$ constants. The W-P finite elements are connected to the slab with $1 \mathrm{D}$ interface elements with different properties in compression and tension, allowing separation from the base.

\subsection{Model parameters}

Elastic material properties are considered in a standard way; concrete $E=32500 \mathrm{MPa}, \nu=0.2$, 


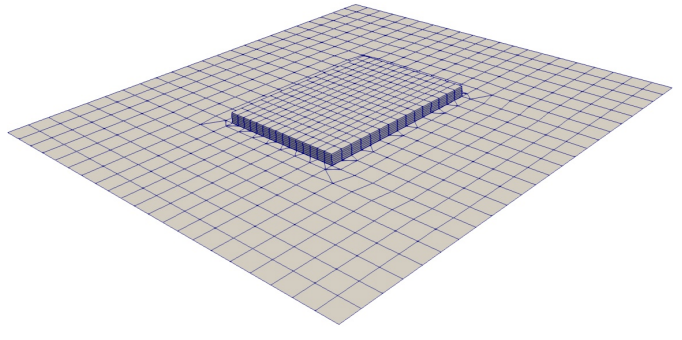

Figure 6. Mesh for the mechanical model.

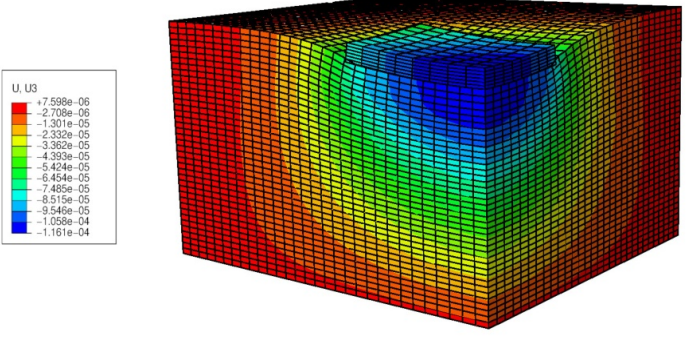

FiguRE 7. Nodal displacement in vertical direction for $3 \mathrm{D}$ continuum model.

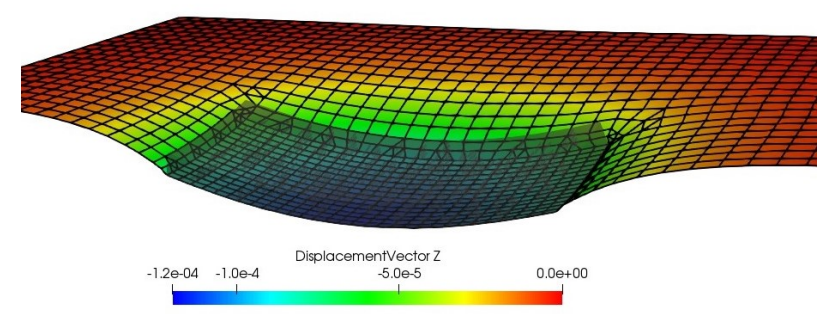

Figure 8. Nodal displacement in z direction for W-P model.

$\alpha=10^{-6} 1 /{ }^{\circ} \mathrm{C}$. The Winkler-Pasternak model has $C_{1}=70.0 \mathrm{MNm}^{-3} C_{2}=60.0 \mathrm{MNm}^{-1}$. Geometry and mesh is created in Salome preprocessor, see Figure 6. Interface material has low shear stiffness $\left(k_{s}=0.01 \mathrm{MN} / \mathrm{m}\right)$, high stiffness in compression $\left(k_{n}=2000 \mathrm{MN} / \mathrm{m}\right)$ while in tension only $0.2 \mathrm{MN} / \mathrm{m}$.

\subsection{Calibrating Winkler-Pasternak CONSTANTS}

W-P elements save significant degrees of freedom and computation time. It is cumbersome to determine the two elastic constants $C_{1}$ and $C_{2}$, in this case the blind prediction is done based on the $3 \mathrm{D}$ continuum model and then a correction was made, based on the static load tests carried out with two heavy trucks.

In the blind prediction with $3 \mathrm{D}$ continuum model in Figure 7, we use elastic parameters that are given by TP170 [1]. The foundation system consists of three

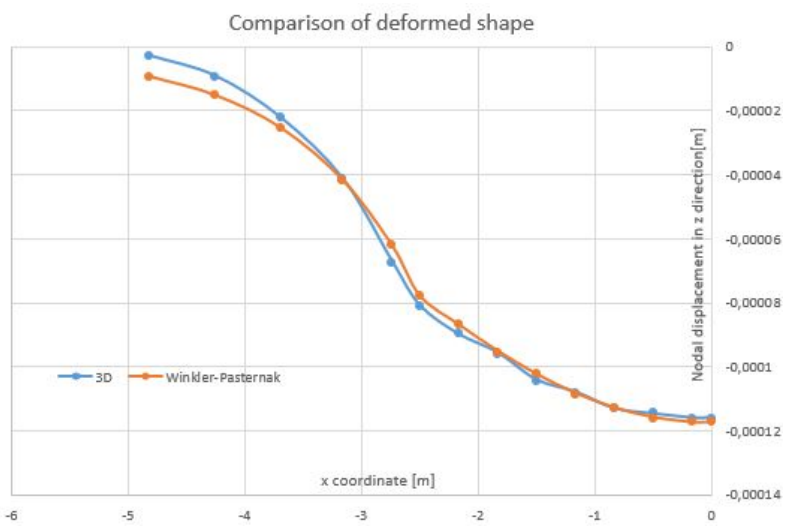

Figure 9. Comparison of deformed shape.
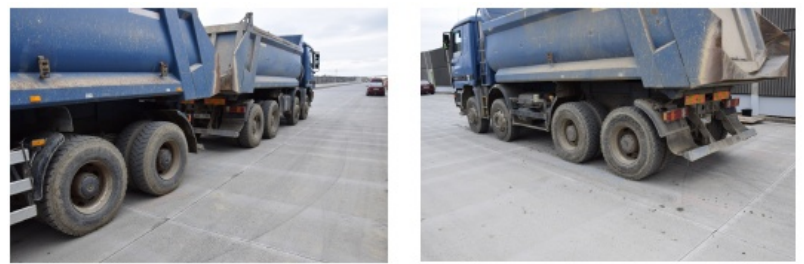

Figure 10. Trucks positioning for static load test.

materials MZK (compacted gravel with defined moisture), $\mathrm{SD}_{A}$ (vibrated gravel) and soil PI. We expect that the soil properties meet the PI requirements, based on used combination of foundation system, that is taken from pavement catalogue, that can be found in TP170 and is commonly used for pavement design in the Czech Republic. For MZK we use these elastic properties $E=600 \mathrm{MPa}, \nu=0.25$, for $\check{\mathrm{S}}_{A} E=$ $400 \mathrm{MPa}, \nu=0.3$ and for PI soil $E=120 \mathrm{MPa}, \nu=$ 0.325 . The calibrated parameters were found as $C_{1}=$ $34.6 \mathrm{MNm}^{-3} C_{2}=50.0 \mathrm{MNm}^{-1}$, based on iterative comparison of deformed shape in Figure 9, 3D continuum model in Figure 7 and W-P model in Figure 8 ,

\subsection{STATIC TRUCK LOAD TEST}

The static truck load test on the experimental slab took place Apr 29, 2019. The loading was realised with 2 trucks, each with 4 axles, the weight of trucks was $37.08 \mathrm{t}$ and $38.42 \mathrm{t}$. The goal of the static load test was to induce the concave shape, with the truck wheels loading the edges of the slab and the convex shape with trucks loading the centre of the slab. This was reconstructed with mechanical model, with distributed local load representing the truck wheels.

New W-P constants were determined, based on comparison with the strains from mechanical model. We obtained $C_{1}=70 \mathrm{MNm}^{-3}$ and $C_{2}=60.0 \mathrm{MNm}^{-1}$, so our presumption was not far. As shown in Figures 11 and 12 for concave and convex deformed shapes, we have quite a good fit in six different measuring positions and the top gages, considering several facts that are influencing the behavior of the slab, such as interaction of neighboring slabs and the fact 

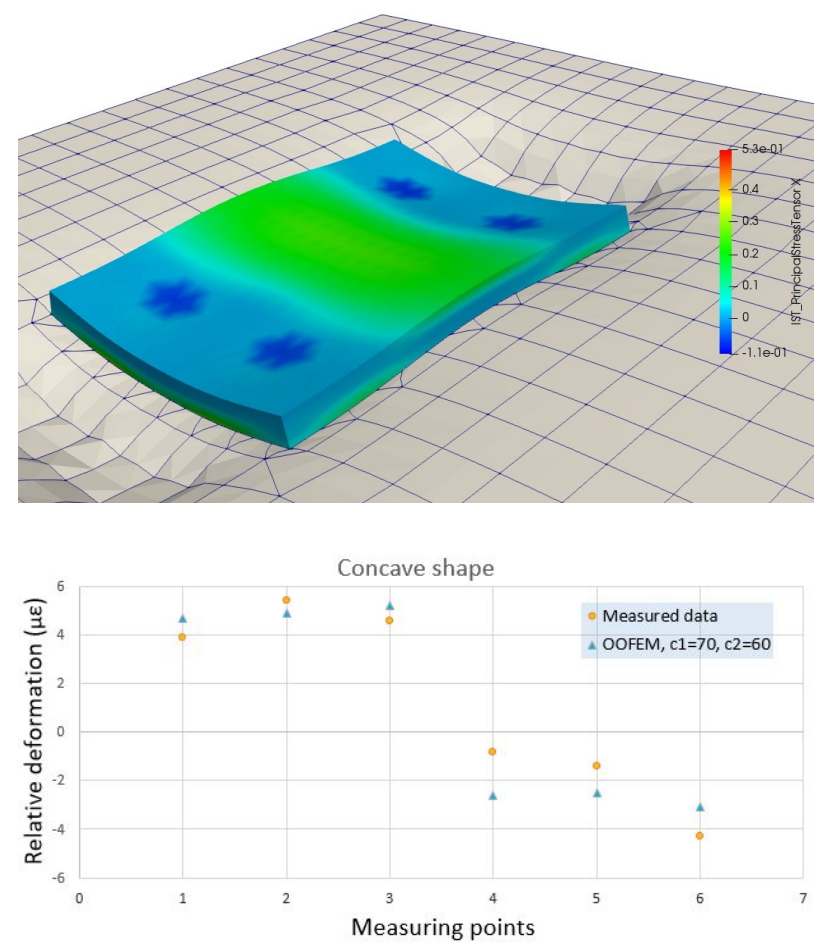

Figure 11. Concave deformed shape simulation (top) and strain validation in 6 different measuring points in the top height level (bottom).

that the foundation system is not perfectly planar.

\section{THERMO-MECHANICAL COUPLED TASK}

The idea of thermo-mechanical model is to solve the two task in the staggered manner, solving the thermal part first and in every step export the temperature field to the mechanical task, where it appears as a loading. It is necessary to set the coefficient of linear thermal expansion $\alpha$. There are 2 important scenarios that can be simulated using this model, the influence of initial casting for strain and the behavior of the concrete pavement under environmental loading.

The thermal model starts 6 hours earlier to ensure, that the temperature field is not influenced with the initial temperature set for every used layer. The mechanical task starts to interact with the temperature field exported from the thermal task. The thermal loading derive typical concave (Fig.13) and convex (Fig.14) deformation shapes. It appears that the thermal load induces higher strains [7] (and consequently stresses) than the wheel load for concrete pavement. It is clear that non-linear temperature profile is too far from commonly prescribed linear gradient used in pavement analysis, leading to unacceptable simplifications.

\section{Future MOdel DEVElOPMENT}

The weakly-coupled thermo-mechanical model is mature for the prediction of actual behavior of concrete
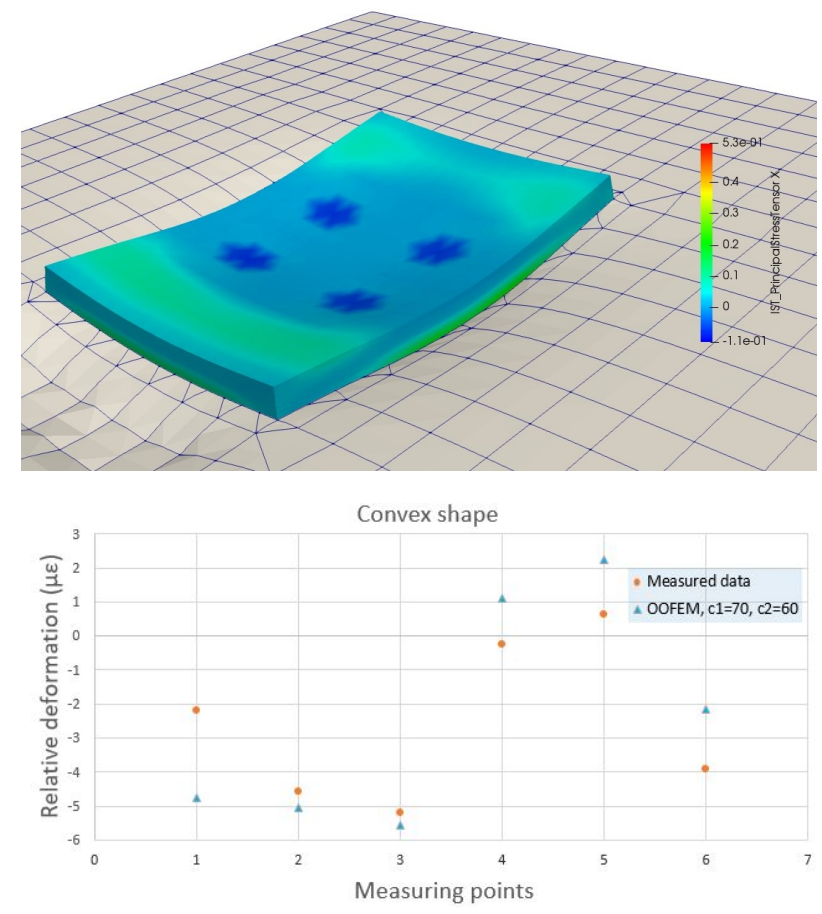

Figure 12. Convex deformed shape simulation (top) and strain validation in 6 different measuring points in the top height level (bottom).

Time: $17.500000 \mathrm{~h}$

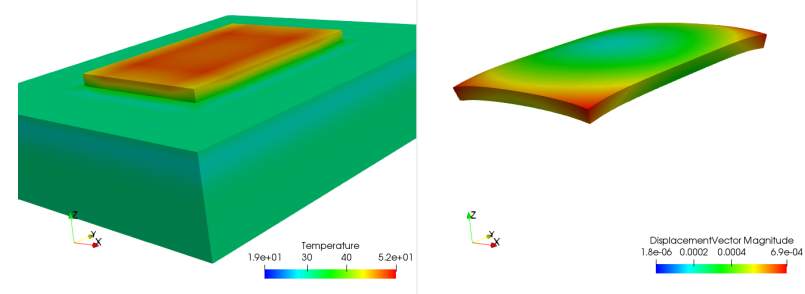

Figure 13. Positive temperature gradient causing concave deformed shape.

Time: $30.000000 \mathrm{~h}$
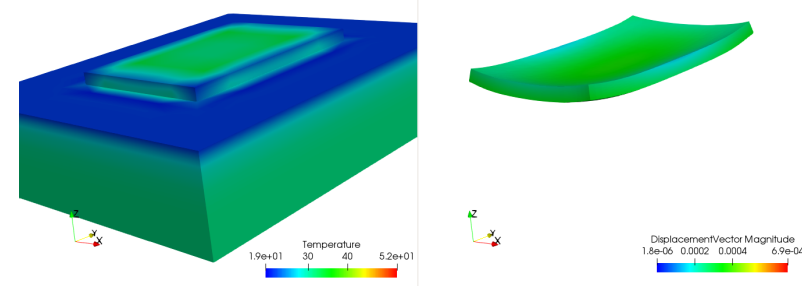

FiguRE 14. Negative temperature gradient causing convex deformed shape. 
pavements and to pinpoint critical aspects influencing the service life. The models allow incorporation of moisture transport, creep and shrinkage phenomena, providing even realistic stresses. They may enter into fatigue calculation, covering combination of thermal and traffic loading.

\section{Conclusion}

This paper deals with thermo-mechanical numerical model for concrete pavement with corresponding validations. There are several identified conditions that influence achieved maximal temperature.

The solution for mechanical task using WinklerPasternak soil elements is presented, with possible method how to determine the $C_{1}$ and $C_{2}$ constants. They were first predicted using $3 \mathrm{D}$ half-space approach and then validated and corrected with static truck load test. Future directions for possible development of the modelling is also presented.

\section{ACKNOWLEDGEMENTS}

We gratefully acknowledge the financial support from the Czech Technical University in Prague, the grant SGS20/107/OHK1/2T/11 and from Technology Agency of the Czech Republic under project TH03020404.

\section{REFERENCES}

[1] J. Kudrna, M. Varaus, F. Luxemburg, L. Vébr, I. Racek, J. Fiedler and A. Artušenko. Navrhování vozovek pozemních komunikací, TP170. Tech. rep., Ministerstvo dopravy, 2004.

[2] A. Ioannides. Concrete pavement analysis: the first eighty years. International Journal of Pavement Engineering 7(4):233-249, 2006.

[3] R. Burrows. The visible and invisible cracking of concrete. Americal Concrete Institute, 1998.

[4] G. De Schutter, L. Taerwe. Degree of hydrationbased description of mechanical properties of early age concrete. Materials and Structures 29(7):335-344, 1996.

[5] B. Patzák. Oofem - an object-oriented simulation tool for advanced modeling of materials and structures. Acta Polytechnica 52(6):59-66, 2012.

[6] B. Patzák, et al. Object Oriented Finite Element Method - OOFEM, since 1993. Http://www.oofem.org.

[7] S. Kim, H. Ceylan, K. Gopalakrishnan. Finite element modeling of environmental effects on rigid pavement deformation. Frontiers of Structural and Civil Engineering 8(2):101-114, 2014. 